\title{
New Effective Technique for Correction of Flat Helix
}

\author{
Mohammed Saad Hasaballah ${ }^{1}$, Ahmed Abdelmoneim Teaima ${ }^{2 *}$, Ossama Mustafa Mady ${ }^{2}$ and Mohammed Salah \\ Mady $^{2}$
}

${ }^{1}$ Assistant Professor of Otorhinolaryngology, Ain Shams University Faculty of Medicine, Cairo, Egypt

${ }^{2}$ Lecturer of Otorhinolaryngology, Ain Shams University Faculty of Medicine, Cairo, Egypt

Submission: June 21, 2019; Published: July 03, 2019

*Corresponding author: Ahmed A Teaima, Assistant Professor, Ain Shams University staff houses Elwaely, Cairo, Egypt

Abstract

Objective: To illustrate our technique in correction of flat helix and its efficacy.

Study Design: Case series

Material \& Methods: Total of 13 patients were operated by our technique, bilateral ears simultaneously. So, 26 ears were included in the study. Follow up postoperatively was done for six months to conclude the efficacy of this technique and its complications

Results: No perichonditis or other complications occurred postoperatively. No complications happened on long term follow up. Patients were satisfied by the results of surgery.

Conclusion: Flat helix is an overlooked deformity with few reports in the literature. Our technique provides simple and effective way for correction without any significant complications.

Keywords: Flat Helix; Auricular Deformity; Otoplasty

Compliance with Ethical Standards

This study was done at Ain Shams University Hospitals. The research involves human participants. All procedures performed in studies involving human participants were in accordance with the ethical standards of the Faculty of Medicine Review Board and with the $1964 \mathrm{Helsinki}$ declaration and its later amendments or comparable ethical standards. Informed consent was obtained from all individual participants included in the study.

\section{Introduction}

Congenital ear deformities include protruding ear, microtia, lop ear, flat helix and others [1]. Any variations from the normal helix shape are obvious [2]. Flat helix is absence of conchal prominence in spite of presence of antihelix [3]. In comparison to other auricular deformities, flat helix is not so common and may be underestimated. So here we represent our case series of correction of this deformity by new and simple technique with less complications. We call it SRCS (Skin Removal Cartilage Scoring) technique.

\section{Methods}

This study was done in Otorhinolaryngology department at Ain Shams University Hospitals from January 2016 to December 2018. Thirteen patients were included. Ages from 6 years old to 22 years old (mean 15 years old), nine are males, four are females. Both sides were done simultaneously. So total 26 ears were operated. The operation time was about twenty-five minutes +/_ten minutes. No need for dressing or hospitalization postoperatively. Patients can return to work from second day.
They are followed up for six months postoperatively to see the results.

\section{Technique}

The operation is done under general anesthesia. Two points are marked on the skin of the lateral surface of the auricle. Both are about 8-10 $\mathrm{mm}$ from the free edge of the auricle.

a) Point $\mathrm{A}$ is at the point of origin of root of helix.

b) Point $\mathrm{B}$ is low in the auricle nearly at the level of antitragus.

Then wedge-shaped incision is done between the two points with maximum width is about $8-10 \mathrm{~mm}$ in adult and $6-8 \mathrm{~mm}$ in child. The posterior limb of the incision is nearly $4-5 \mathrm{~mm}$ from the free edge of the auricle corresponding to the new helix. The two limbs of the incision are nearly parallel (Figure 1).

Local injection of $1 / 200000$ saline adrenaline in the lateral surface of the auricle is done. Then two incisions are done marking this wedge of skin. The land of skin between the 2 incisions is 


\section{Global Journal of Otolaryngology}

dissected and separated from the underlying perichondrium and then excised (Figure 2). Then very important step is to do scoring and cross hatching of the island of cartilage in the area of the removed skin to weaken it and to allow it to bend when we suture the two edges of the skin under tension. Finally, we suture the two edges of the skin under tension. This will create the curvature of the helix in a natural way (Figure 2). It is very important to avoid dissection or separation of the skin from the underlying cartilage in the two edges (don't do undermining of the skin). If you do that, this will lead to the presence of pocket between the skin and the cartilage after closure. Finally, we put small pieces of steristreps in radial manner to support the curved part of the helix in its place
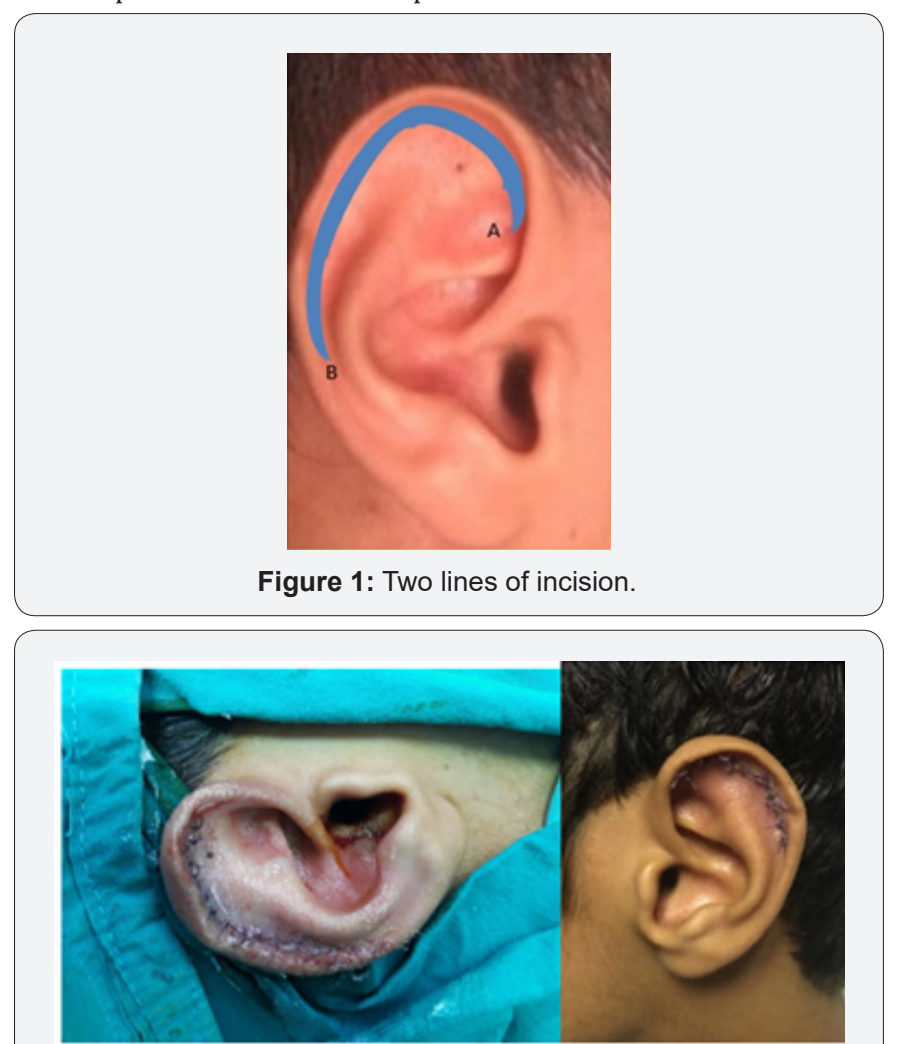

Figure 2: Excision of the skin wedge and Suturing the skin.

Results

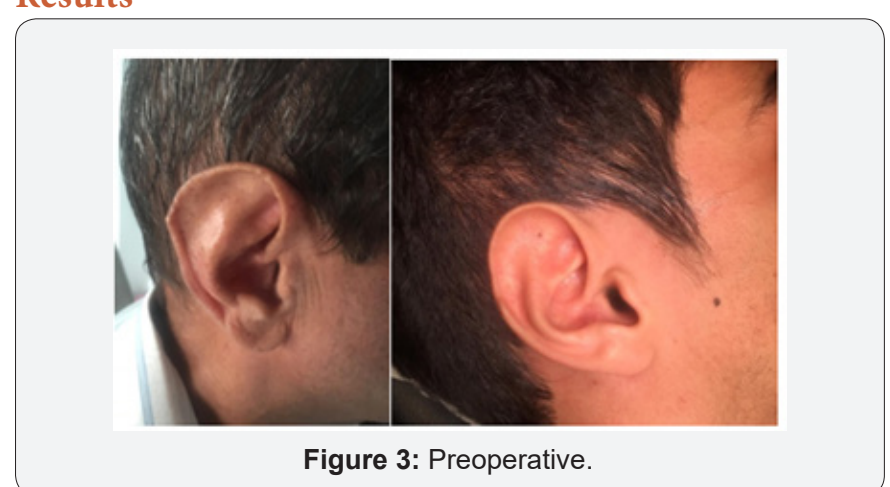

Patients were followed up for six months. Results are very good. No intraoperative complications. No postoperative infection or perichondritis. No pain or auricular hematoma. All patients were satisfied. No recurrence of the deformity. Pre and postoperative photos are provided in Figures $3 \& 4$.

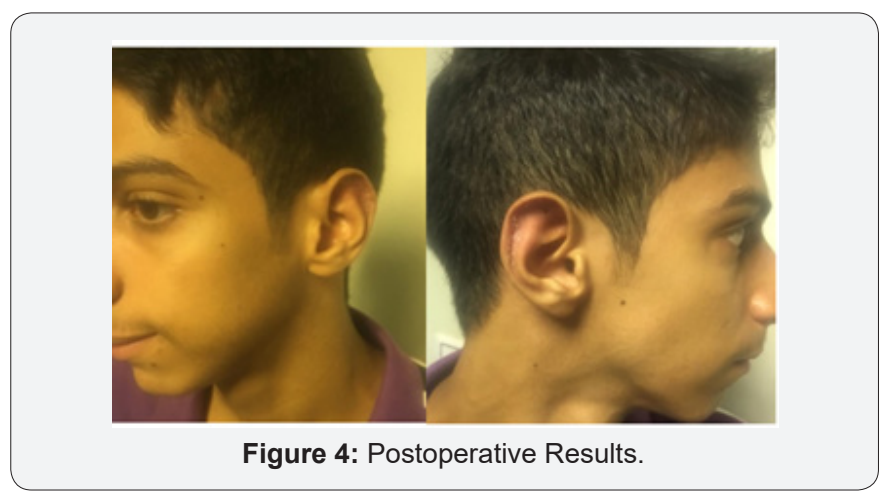

\section{Discussion}

Although helix is significant to the overall shape and appearance of the auricle, relatively little attention has been paid to its deformities. Surgical techniques for correction of these deformities are variable [4]. Ducourtioux was the first to report on flat helix correction [5]. North et al used technique which includes wedge cartilage excision and may result in some complications during healing like the presence of sharp edges and loss of natural auricular curvature [6]. Maurice and Eisbach modified this technique by removing composite small wedges of cartilage and skin ranging from 5 to $10 \mathrm{~mm}$ in width and not exceeding the helix [7]. In contrast to all these, our technique is so simple and allows good correction of flat helix deformity without significant complications like other procedures. It has a short learning curve. It is important to stress that we don't undermine the skin over the helix to avoid the formation of postoperative pocket.

\section{Conclusion}

Flat helix is an overlooked deformity with few reports in the literature. Our technique provides simple and effective way for correction without any significant complications.

\section{References}

1. Bi Y, Lin L, Yang Q Pan B, Zhao Y, et al. (2015) Surgical correction of constricted ear combined with Stahl's ear. J Plast Reconstr Aesthet Surg 68(7): 895-901.

2. Becker D, Lai S, Schipor I, Becker S (2003) Analysis in otoplasty. Facial Plast Surg Clin North Am 11(3):297-305.

3. Wilbrand J, Schaaf H, Streckbein P, Howaldt H (2011) Correction of flat auricular helix. J Plast Reconstr Aesthet Surg 64(12): 335-336.

4. Janis J, Rohrich R, Gutowski K (2005) Otoplasty. Plast Reconstr Surg 115(4): 60e-72e.

5. Ducourtioux JL (1971) A simple procedure for surgical correction of a congenitally absent helix. Ann Chir Plast 16(1): 60-62.

6. North JF, Broadbent RG (1977) Correcting the flat helix. Br J Plast Surg 30(4): 310 .

7. Maurice PF, Eisbach KJ (2005) Aesthetic otoplasty: wedge excision of a flattened helix to create a helical curl. Arch Facial Plast Surg 7(3): 195-197. 
(C) (i) Commons Attribution 4.0 License

(C) (1) Commons Attribution 4.0 License
Your next submission with Juniper Publishers will reach you the below assets

- Quality Editorial service

- Swift Peer Review

- Reprints availability

- E-prints Service

- Manuscript Podcast for convenient understanding

- Global attainment for your research

- Manuscript accessibility in different formats ( Pdf, E-pub, Full Text, Audio)

- Unceasing customer service

Track the below URL for one-step submission https://juniperpublishers.com/online-submission.php 